\title{
Improvement of balance in progressive degenerative cerebellar ataxias after Ayurvedic therapy: A preliminary report
}

\author{
S. J. Sriranjini, Pramod Kumar Pal, K. V. D evidas', Selva Ganpathy² \\ Departments of Neurology, ${ }^{1}$ Advanced Ayurvedic Research Unit, and ${ }^{2}$ Psychiatric and Neurological Rehabilitation, National Institute \\ of Mental Health and Neurosciences, Bangalore, India
}

Address for correspondence: Dr. Pramod Kumar Pal, Department of Neurology, National Institute of Mental Health and Neurosciences, Bangalore, India. E-mail: pal.pramod@ rediffmail.com

DOI: $10.4103 / 0028-3886.51286$

\begin{abstract}
Abstradt
Background: The treatment options for improving the balance in degenerative cerebellar ataxias are very few. Ayurvedic texts have described diverse treatment regimens for this disease. Aims: To determine the change in balance indices, if any, by dynamic posturography (Biodex Balance System, USA) in progressive cerebellar ataxia following Ayurvedic treatment. Materials and Methods: We performed a preliminary open labelled study on ten patients diagnosed with progressive cerebellar ataxia. The patients were treated over a period of one month. Treatment consisted of Shirobasti (therapeutic retention of medicament over the scalp) in male patients and Shirodhara (pouring of a steady stream of medicament on the forehead) in female patients with Dhanvantaram tailam (medicated oil) for 45 minutes daily, followed by Abhyanga (methodical massage) with Dhanvantaram tailam and Bhashpa sweda (steam bath), for 14 days. In addition, the treatment also consisted Abhyantara aushadha (oral medicines) of Maharasnadi kashayam $15 \mathrm{ml}$ thrice daily, Dhanvantaram capsules $10 \mathrm{I}$ two capsules thrice daily, and Ashwagandha tablet $500 \mathrm{mg}$ one tablet thrice daily, for one month. The patients were assessed on the Biodex balance system before and after the treatment. Results were analyzed using paired samples ' $t$ ' test. Results: All patients tolerated the treatment well without any adverse events and reported subjective improvement in walking. There was a statistically significant improvement in the overall and anteroposterior balance indices of dynamic stability. Conclusions: Over the short period of the present study, Ayurvedic therapy was found to be safe and, showed improvement in the balance in patients with progressive degenerative cerebellar ataxia. Further randomized placebo-control double-blind studies are needed to validate the results.
\end{abstract}

Key words: A yurveda, balance, cerebellar ataxia, shirobasti, shirod hara

\section{Introduction}

Comprehensive treatment of progressive cerebellar ataxias has remained elusive to a large extent. There is as yet no approved drugs or disease-modifying therapies for this problem ${ }^{[1]}$ and till date, there is no documented Allopathic treatment effective for cerebellar ataxias. A yurveda describes this condition as kaphavrita vyana vata (occlusion of vyana vata by kapha dosha) under vata vyadhi (neurological diseases) ${ }^{[2]}$ and specific treatment regimens ${ }^{[2-6]}$ have been described to combat the various symptoms seen in the course of the disease. The aim of this study was to objectively assess the improvement in balance in progressive degenerative cerebellar ataxias following one such mode of treatment.

\section{Materials and M ethods}

Design and participants

This study was conducted at the Ayurvedic Research Unit at our institute. The A yurvedic treatments used in the present study are in practice in India for many years. The treatment protocol involved administration of A shwagandha tablet, $D$ hanvantaram tailam, and $M$ aharasnadi 
kashayam, which are routinely used substances in various vata disorders in A yurveda. These medicines are vatahara, that is, for alleviating neurological disorders that are considered as vata disorders in A yurveda and they are also used as balya and pushtiprada, meant for any degenerative disorders. The therapeutic regimen of abhyanga (massage), svedana (sudation), shirobasti, and shirodhara (specific treatments for the head) are routinely used in neurological disorders. Considering the above facts, the institutional ethical clearance was not sought for this study. Only those patients who verbally consented to receive this form of treatment were considered for the study.

For inclusion in this study, patients with chronic degenerative ataxias in the age group of $12-60$ years, who had progressive worsening of symptoms despite various Allopathic treatments and were willing to consider A yurvedic treatment, were recruited. Patients with ataxia secondary to tumor, infection, stroke (ischemia or hemorrhage), demyelination, craniovertebro-junction anomalies, alcohol, hypothyroidism, drugs, pregnancy and postpartum period, renal, hepatic, and significant cardiac dysfunctions, and severe dementia were excluded from the study. Ten patients fulfilled the above inclusion and exclusion criteria and were recruited in the study. A detailed neurological examination of all the patients was performed. Genotyping was performed to determine the CAG repeat lengths.

\section{Intervention}

Patients were admitted to the Ayurvedic Research Unit at our institute for a period of one month and A yurvedic treatment was administered, which consisted of the following:

\section{Shirobasti (therapeutic retention of oil over the scalp)}

This was done to the male patients for 45 minutes daily, for 14 days. ${ }^{[5]}$ The patients' heads were shaven prior to the treatment program. The patients were made to sit comfortably on a chair. A unique hollow cylindrical container made of leather was placed on the head and the area of the container in contact with the scalp was sealed with a paste of black gram powder to prevent leaking of the oil. ${ }^{[2]}$ Two-and-a-half liters of D hanvantaram tailam ${ }^{[2]}$ was warmed on a water bath to $95-100^{\circ} \mathrm{F}$ (depending on the patients' tolerance) and cautiously poured into the container. As the oil became cold, it was removed and replaced with fresh warm oil. The same process was repeated over a 45-minute period, maintaining the temperature of the oil constantly between $95-100^{\circ} \mathrm{F} \cdot{ }^{[7]}$

\section{Shirodhara (pouring of a steady stream of oil on the forehead}

This procedure was performed in female patients for 45 minutes daily, for 14 days. ${ }^{[5]}$ The patients were made to lie supine on the Dhara table (customized unique table) and the eyes were covered with gauze to prevent oil dripping into the eyes. Two-and-a-half liters of D hanvantaram tailam was warmed up to $95-100^{\circ} \mathrm{F}$ on a water bath and taken in the D hara patra (special vessel with a small hole in the center). A steady stream of the oil was made to fall on the forehead of the patient from a height of three inches. As the oil dripped on to the table, it was collected in a vessel kept underneath the table and reheated. This warm oil was again poured into the $D$ hara patra. Care was taken to ensure a continuous flow of oil. ${ }^{[7]}$

\section{Abhyanga (massage)}

After Shirodhara and Shirobasti, A bhyanga (methodical massage $)^{[7]}$ of the entire body was performed with D hanvantaram tailam.

\section{Svedana (sudation)}

Bhashpa sveda variety of Svedana was done. The patient was made to sit in a Bhashpa svedana yantra (customized wooden box $)^{[7]}$ into which warm vapors were passed. This induced perspiration in the patient. This was continued for 10-15 minutes depending on the patient's tolerance level.

\section{Abhyantara aushadha (oral medicines)}

All the patients were administered the following internal medicines for one month.

- D hanvantaram capsules ${ }^{[2]} 101(2 \mathrm{ml})$ : Two capsules t.i.d.

- A shwagandha tablet ${ }^{[6]} 500$ mg: One tablet t.i.d.

- $\quad M$ aharasnadi kashayam: ${ }^{[4]} 15 \mathrm{ml}$ t.i.d.

Medicines were procured from The Indian Medical Practitioners Cooperative Pharmacy and Stores Ltd., Chennai, India.

The details of the ingredients of the above Ayurvedic preparations are given in the Appendix.

\section{Outcome measures}

The study endpoints assessed and analyzed for each patient consisted of objective testing of balance using dynamic posturography (Biodex Balance System (BBS), USA). Patients were tested for dynamic stability and limits of stability (LOS) before and after the treatment by the same coinvestigator in this study. LOS is defined as the area which the subject safely moves without changing the base of support. To test LOS, the patients were asked to shift their center of mass without changing foot position into eight targets positioned in an ellipse, the perimeter of which corresponded to $50 \%$ of the LOS. The direction of the target was indicated on the screen by a blinking target which appeared at random 
in different directions, each target being selected only once. The maximum movement time allowed was 300 seconds. Postural sway was recorded and the area of sway calculated and expressed as percentage of the patients' LOS. The balance indices which included the overall balance index (OBI), anteroposterior index (API), and mediolateral index (MLI), and the LOS scores as computed and given by the system were collected and used for further analysis.

\section{Statistical analysis}

Results were analyzed using paired samples ' $t$ ' test.

\section{Results}

There were three women and seven men who participated in the study (mean (SD) age: 24.2 years (9.4), height: $162.6 \mathrm{~cm}(9.8)$, and weight: $47.0 \mathrm{~kg}(7.5))$. The mean age at onset of illness was $19.9 \pm 10.6$ years and the duration of illness $4.4 \pm 3.8$ years. Genotyping confirmed a diagnosis of SCA1 and SCA2 in two patients each, SCA3 in one patient, and the remaining five patients were negative for SCA1,
SCA2, and SCA3. All the patients were able to complete the treatment and no one had any adverse events.

Prior to the treatment, all ten patients had abnormal balance indices. Sixty percent of the patients had abnormal OBI and API, $20 \%$ had abnormality of only OBI, $10 \%$ had abnormalities of OBI and MLI, and in the rest $10 \%$ all the balance indices were abnormal. After the treatment, $40 \%$ of the patients had normal balance indices, 30\% had abnormal OBI and API, 20\% showed abnormality in all indices, and $10 \%$ had only OBI abnormality. Figures 1a-1c shows the actual values of all the balance indices of each patient before and after treatment. There was a statistically significant improvement in the mean values of OBI and API balance indices $(P=0.007, P=0.047$, respectively), but not of MLI [Figure 1d].

Prior to the treatment, eight patients were able to complete the LOS test in the stipulated time. The two patients who were unable to complete the LOS test before treatment were able to do so after the treatment. However, one

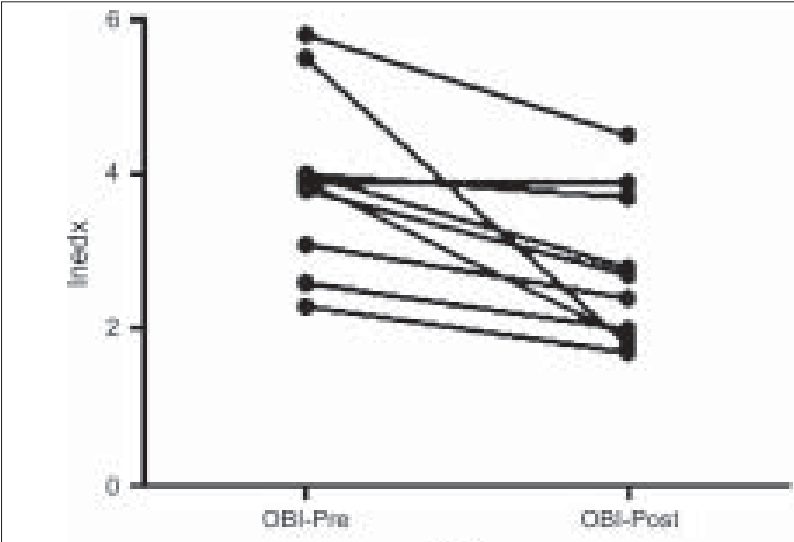

(a)

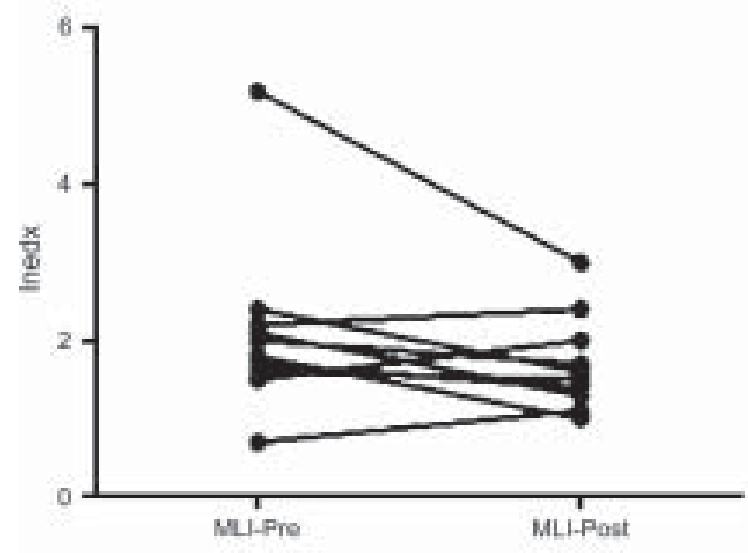

(c)

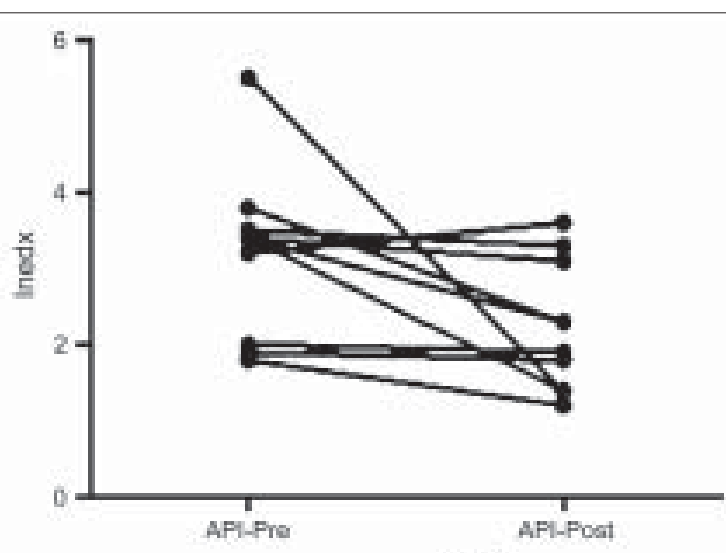

(b)

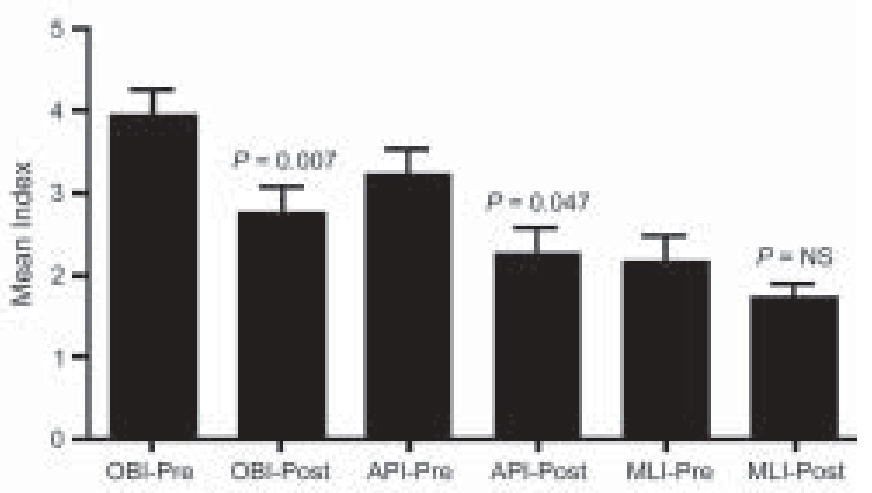

(d)

Figure 1: (a) Improvement in overall balance index (OBI) of individual patients following Ayurvedic treatment; (b) Improvement in anteroposterior index (API) of individual patients following Ayurvedic treatment; (c) Mediolateral index (MLI) before and after Ayurvedic treatment; (d) Mean values of OBI, API, and MLI before and after treatment 
patient who was able to perform the assessment before treatment was unable to do so following the treatment. The mean time taken for completing the test reduced from $237.6 \pm 59.7$ seconds to $215.7 \pm 85.0$ seconds. However, there was statistically no significant change in any of the parameters of LOS following treatment.

\section{Discussion}

In this study, we have reported our preliminary observations of the effect of Ayurvedic treatment in patients with degenerative cerebellar ataxia. Though molecular genetic research has completely revolutionized the way in which the progressive cerebellar ataxias are classified and diagnosed, it is yet to produce effective gene-based, neuroprotective, or neurorestorative therapies ${ }^{[8]}$ With due acknowledgement of the limitations of open-label study on a small heterogeneous group of progressive degenerative ataxias, we report encouraging observations in treatment of this debilitating disorder for which there is no effective therapy till date. Though A yurvedic treatment has been reported to be effective in other neurodegenerative conditions, such as Parkinson's disease, ${ }^{[9]}$ to the best of our knowledge, there are no reports of similar beneficial treatment in progressive degenerative cerebellar ataxias.

Dynamic posturography and BBS have been validated in earlier studies. ${ }^{[10-12]}$ In our study, there was an objective improvement in balance after one month of A yurvedic therapy. While before treatment all the patients had one or more abnormal balance indices, following treatment, $40 \%$ of patients showed normal balance indices (all three). The mean values of OBI and API also significantly improved after treatment. The MLI was normal in eight patients prior to the treatment. In the remaining two patients, the mean MLI improved after treatment ( $3.8 \pm 1.98$ to $2.3 \pm 0.99)$. On the contrary, we did not observe any significant change in the LOS parameters.

A yurveda stresses on a holistic approach to diseases, and hence, treatment is aimed at both the dosha (causal factor) and the vyadhi (disease). The A yurvedic treatment administered in the present study is also on similar lines. Predicting the exact mode of action of the treatment is not feasible due to the complexity of the treatment regimen. However, a hypothesis on the possible mode of action has been postulated based on the descriptions in A yurvedic classics and existing literature on these therapies. ${ }^{[13-21]}$

Shirodhara, Shirobasti, A bhyanga, and Svedana are balya (promote strength) and vatahara (pacify morbid vata). Svedana also aids kaphaharana (pacifies morbid kapha). This promotes samprapti vighattana (undoing the pathogenesis) and plays a crucial role in bringing about the desired result. Therapeutic oil massage is known to promote growth and development in neonates via transcutaneous absorption of the nutrients. ${ }^{[13-15]}$ These therapies enhance muscle power and thus may have contributed to the improved performance in the balance parameters. Oxidative stress plays a vital role in the pathogenesis of such degenerative disorders of the brain. ${ }^{[16]}$ Thermal therapy is known to enhance antioxidant functions such as the activities of superoxidase dismutase. ${ }^{[17]}$ Hence, Svedana procedure may also have facilitated a similar action. Shirodhara has been shown to have anxiolytic, sympatholytic, and immunopotentient effects on patients of anxiety. ${ }^{[18,19]} \mathrm{A}$ possible reduction in the anxiety coupled with other effects may have resulted in better performance. A shvagandha (W ithania somnifera Linn.), Bala (Sida cordifolia Linn.), and other ingredients in $M$ aharasnadi kashayam are known antioxidants,, ${ }^{[20]}$ and thus may contribute to prevent and/or revert the pathogenesis. Bala is also the chief ingredient of D hanvantaram tailam. Krishnamurthy and Telles reported improvement in the mobility, as assessed by timed up and go (TUG) test in older people (60-95 years), after treatment with a polyherbal formulation containing A shwagandha and Bala. ${ }^{[21]}$ The authors attributed this to a possible improvement in the muscle strength, similar to that reported in A yurvedic classics.

In summary, the present study is a preliminary report of the objective evaluation of the efficacy of A yurvedic therapy in improving balance. The results are encouraging and warrant further structured studies to objectively assess the efficacy of different modalities of A yurvedic treatment in degenerative ataxias where till date contemporary medicines do not have much to offer.

\section{Acknowledgment}

The authors acknowledge the Indian Council of Medical Research, India, for partial financial support and the staff of Ayurvedic Research Unit, NIMHANS, Bangalore, for their help in conducting the study.

\section{References}

1. Perlman SL. Symptomatic and disease-modifying therapy for the progressive ataxias. Neurologist 2004;10:275-89.

2. Acharya VriddhaVagbhata. Dr. DV Pandit Rao, Vd.Ayodhya Pandey, editors. In: Ashtanga sangraha. 1991. New Delhi, Kendriya Ayurveda evam siddha Anusandhana Parishat (CCRAS).

3. Acharya Charaka, Dridabala, Chakrapanidatta. Vaidya Yadavji Trikamji Acharya, editor. 5. In: The Charaka Samhita of Agnivesha. 2008. Munshiram Manoharlal Publishers Pvt. Ltd; 2008.

4. Sen GD. Bhaishajya ratnavali. Bombay: Khemraj Srikrishnadas Prakashan; 2001.

5. Acharya Sushruta, Dalhanacharya, Gayadasacharya. In: Acharya YT, Acharya NR, editors. Sushruta samhita. Varanasi, Uttar Pradesh: Krishnadas Academy; 1998.

6. Sri Bhavamishra. In: Mishra B, editor. Bhavaprakasha. Varanasi: Chaukhambha Sanskrita Samsthana; 1997. 
7. Kasture HS. Ayurvediya panchakarma vijnana. Nagpur: Sri Baidyanath Ayurveda Bhavan; 1997.

8. Perlman SL. Cerebellar Ataxia. Curr Treat Options Neurol 2000;2: $215-24$.

9. Nagashayana N, Sankarankutty P, Nampoothiri MR, Mohan PK, Mohanakumar KP. Association of L-DOPA with recovery following Ayurveda medication in Parkinson's disease. J Neurol Sci 2000;176:124-7.

10. Arnold BL, Schmitz RJ. Examination of Balance Measures Produced by the Biodex Stability System. J Athl Train 1998;33:323-7.

11. Schmitz R, Arnold B. Intertester and intratester reliability of the Biodex Stability System. J Sport Rehabil 1998;7:95-101.

12. Pincivero DM, Lephart SM, Henry TJ. Learning effects and reliability of the Biodex Stability System. J Athl Train 1995;30:S35.

13. Arora J, Kumar A, Ramji S. Effect of oil massage on growth and neurobehavior in very low birth weight preterm neonates. Indian Pediatr 2005;42:1092-100.

14. Sankaranarayanan K, Mondkar JA, Chauhan MM, Masearenhas BM, Mainkar AR, Salvi RY. Oil massage in neonates: An open randomized controlled study of coconut versus mineral oil. Indian Pediatr $2005 ; 42: 877-84$.

15. Solanki K, Matnani M, Kale M, Joshi K, Bavdekar A, Bhave S, et al. Transcutaneous absorption of topically massaged oil in neonates. Indian Pediatr 2005;42:998-1005.
16. Kidd PM. Neurodegeneration from mitochondrial insufficiency: Nutrients, stem cells, growth factors, and prospects for brain rebuilding using integrative management. Altern Med Rev 2005;10:268-93.

17. Yamaoka K, Mitsunobu F, Hanamoto K, Shibuya K, Mori S, Tanizaki Y, et al. Biochemical comparison between radon effects and thermal effects on humans in radon hot spring therapy. J Radiat Res (Tokyo) 2004;45:83-8.

18. Kazuo U, Feng-Hao X, Takashi T, Yukiko T, Hiroko O, Tatsuya H. Psychological mechanism of traditional healing technique performed by the healing robot through the life information field. J Intl Soc Life Info Sci (ISLIS) 2004;22:169-77.

19. Uebaba K, Xu FH, Ogawa H, Tatsuse T, Wang BH, Hisajima T, et al. Psychoneuroimmunologic effects of Ayurvedic oil-dripping treatment J Altern Complement Med 2008;14:1189-98.

20. Vaidya AD, Devasagayam TP. Current Status of Herbal Drugs in India: An Overview. J Clin Biochem Nutr 2007;41:1-11.

21. Krishnamurthy M, Telles S. Effects of Yoga and an Ayurveda preparation on gait, balance and mobility in older persons. Med Sci Monit 2007;13:LE19-20

Accepted on 31-03-2009

Source of Support: Partial financial support from Indian Council of Medical Research, Conflict of Interest: None declared.

\section{Appendix: List of ingredients}

\begin{tabular}{|c|c|c|c|}
\hline Sanskrit name & Latin name & Sanskrit name & Latin name \\
\hline Bala & Sida cordifolia Linn. & Sariva & Hemedismus indicus $L$. \\
\hline Ksheera & Milk & Kushta & Saussurea lappa C.B.Cl \\
\hline Yava & Hordeum vulgare Linn. & Tagara & Valeriana wallichii DC \\
\hline Kola & Zizyphus jujuba & Saindhava & Rock salt \\
\hline Kulattha & Dolichos biflorus Lamk. & Shaileya & Parmelia perlata \\
\hline Shalaparni & Desmodium gangeticum Linn. & Vacha & Acorus calamus Linn. \\
\hline Prishnaparni & Uraria picta Sesv. & Aguru & Aqualaria agallocha Roxb. \\
\hline Brihati & Solanum indicum Linn. & Punarnava & Boerhavia diffusa Linn. \\
\hline Gokshura & Tribulus terristris Linn. & Ashvagandha & Withania somnifera Linn. \\
\hline Kantakari & Solanum xanthocarpum Linn. & Vari & Cyperus rotundus Linn. \\
\hline Shonaka & Oroxylum indicum Linn. & Kshirashukla & Ipomea digitata Linn. \\
\hline Kashmari & Gmelina arborea & Yashti & Glycerrhiza glabra Linn. \\
\hline Patala & Stereospermum suaveleons DC. & Haritaki & Terminalia chebula Retz. and Willd \\
\hline Bilva & Aegle marmelos Linn. & Vibhitaki & Terminalia bellerica Roxb. \\
\hline Agnimantha & Premna integrifolia Linn. & Amalaki & Phyllanthus emblica Linn. \\
\hline Meda, Mahameda substituted with Shatavari & Asperagus racemosus Willd. & Shatahva & Anethum sowa Kurz. \\
\hline Jivaka, Rishabhaka substituted with Vidari & Pueraria tuberosa DC & Shurpaparni & Phaseoulus trilobus Ait. \\
\hline Daru & Berberis aristata DC. & Tvak & Cinnamomum zeylanicum Blume \\
\hline Manjishta & Rubia cordifolia Linn. & Ela & Eletteria cardamomum Linn. \\
\hline Kakoli, Kshirakakoli substituted with Ashwagandha & Withania somnifera Linn. & Patra & Cinnamomum tamala Nees and Ebum \\
\hline Chandana & Santalum album Linn. & Tila taila & Oil of Sesamum indicum Linn. \\
\hline
\end{tabular}


Dhanvantaram capsules $101^{[2]}$

Same oil as above, processed repeatedly for 101 times.

Maharasnadi kashayam ${ }^{[4]}$

\begin{tabular}{|c|c|c|c|}
\hline Sanskrit name & Latin name & Sanskrit name & Latin name \\
\hline Rasna & Pluchea lancelota Linn. & Punarnava & Boerhavia diffusa Linn. \\
\hline Vatari & Ricinus communis Linn. & Ashwagandha & Withania somnifera Linn. \\
\hline Vasaka & Adhatoda vasica Nees. & Amruta & Tinospora cordifolia Willd. \\
\hline Duralabha & Tragia involucrate Linn. & Krishna & Piper longum Linn. \\
\hline Shati & Kaempferia galanga Linn. & Vriddhadaru & Argyreia nervosa Burm.f.Boj \\
\hline Daruharidra & Berberis aristata DC. & Shatavari & Asperagus racemosus Willd. \\
\hline Bala & Sida cordifolia Linn. & Vacha & Acorus calamus Linn. \\
\hline Musta & Cyperus rotundus Linn. & Sahachara & Barleria cristata Linn. \\
\hline Nagara & Zingiber officinale Rosc. & Chavika & Piper chaba W.Hunter \\
\hline Ativisha & Aconitum heterophyllum Well & Brihati & Solanum indicum Linn. \\
\hline Abhaya & Terminalia chebula Retz. and Willd. & Kantakari & Solanum xanthocarpum Linn. \\
\hline Svadamshtra & Tribulus terristris Linn. & Shunti & Zingiber officinale Rosc. \\
\hline Vyadhighata & Garcinica indica Roxb. & Alambusha & Biophytum sensitivum Linn. \\
\hline Misi & Anethum sowa Kurz. & Ajamoda & Trachyspermum roxburghianum DC. \\
\hline Dhanya & Coriandrum sativum Linn. & Jala & Water \\
\hline
\end{tabular}

Ashwagandha tablet ${ }^{[6]}$

Fine powder of A shwagandha (W ithania somnifera Linn.) 